\title{
Studies on Focal Adhesion Kinase in human breast cancer cell MDA-MB-231
}

\author{
Kirat Kumar Ganguly ${ }^{1}$, Triparna Sen ${ }^{1}$, Sekhar Pal ${ }^{1}$, Jaydip Biswas ${ }^{2}$, Amitava Chatterjee ${ }^{{ }^{*}}$ \\ ${ }^{1}$ Department of Receptor Biology \& Tumor Metastasis, Chittaranjan National Cancer Institute, Kolkata, India \\ ${ }^{2}$ Department of Surgical Oncology, Chittaranjan National Cancer Institute, Kolkata, India \\ Email: ${ }^{*}$ amitava_chatter@yahoo.co.in
}

Received 9 November 2011; revised 18 December 2011; accepted 27 December 2011

\begin{abstract}
AIM: 1) To study the participation of Focal Adhesion Kinase (FAK) in regulation of Breast Cancer cell migration in relation with MMP-9 and other signaling proteins; 2) To study the effect of some natural products on FAK. METHODS: Cell culture, Western Blot, Immunoprecipitation, Immunocytochemistry, Zymography, SiRNA transfection, RT-PCR, Real-Time PCR. RESULTS: For our study on FAK, we selected invasive Breast Cancer cell line MDA-MB-231 and treated the cells with Fibronectin (FN). Treatment of FN was found to increase FAK expression, phosphorylation (Tyr 397). FAK was found to be involved in regulation of breast cancer cell migration and MMP-9 expression, activity. Fibronectin increases association of FAK with integrin $\alpha 5 \beta 1$, Paxillin, Actin, ERK, PI3K and localization at Focal Adhesion sites. FAK was found to be involved in modulation of ERK and PI3K phosphorylation. Moreover, FAK signal was found to be transduced through ERK and PI3K, which modulate MMP-9 and thereby cell migration. CONCLUSION: FAK expression, phosphorylation and processing are induced in response to Cell-ECM interactions. Integrin $\alpha 5 \beta 1$ is involved in FN induced FAK phosphorylation. FAK is a potent regulator of MMP-9 expression and activity. FAK is involved in regulation of ERK and PI3K phosphorylation. ERK and PI3K are involved in FAK regulated MMP-9 expression \& activity. FAK regulates MMP-9 expression and activity and thereby migration of human breast cancer cell. By the regulation of FAK, cell attachment and migration may be regulated by Curcumin, ATRA or EGCG treatment. It may be concluded that invasive potential of breast cancer cells may be modulated by regulation of FAK.
\end{abstract}

Keywords: FAK; Fibronectin; MMP-9; Cell Migration; Breast Cancer

\footnotetext{
"Corresponding author.
}

\section{INTRODUCTION}

One of the common crucial events for cell migration, survival, apoptosis or cell proliferation is cell attachment with Extra Cellular Matrix (ECM). Integrins are the receptors through which cells attach with ECM. Focal Adhesion Kinase (FAK) transmits the signal, produced as a result of Integrin-ECM binding, to cell-interior. FAK is a non-receptor protein tyrosine kinase of $125 \mathrm{kD}$ which directly interacts with $\beta$-subunit of integrin molecule, resides within the Focal Adhesion complex and initiates Integrin mediated signaling. FAK is situated at the signaling junctions where information comes from mainly four sources-ECM-integrin interaction, growth factor signaling, G-protein coupled receptor signaling and mechanical forces imposed on the cell $[1,2]$. After FAK activation, it interacts with a number of signaling molecules which situate FAK at the crossroad of different signaling pathway [3]. FAK transduces signal from ECM to the cell interior through a series phosphorylation and dephosphorylation of different signaling proteins. Experiments after depletion of FAK through different techniques have shown its active participation in different cellular activities like cell attachment, cell survival and apoptosis, cell proliferation etc [4-6]. Overexpression and overactivation of FAK is found in several types and different stages of cancers, which indicate involvement of FAK in cancer progression [7-10].

Matrix Metalloproteinases (MMP) are a family of zinc dependent enzymes responsible for degradation of ECM including basement membrane collagen, interstitial collagens, Fibronectin (FN), and various proteoglycans both in physiological and pathological conditions [10]. Reports have shown that there are several ways of MMP-9 activation. The processes involve molecules like MMP13, MMP-3 or TNF $\alpha$, and mechanism e.g "cysteine switch" [11-15]. Segarra et al. have shown involvement of FAK in the regulation of MMP-9 production and release in T Lymphoid model [16].

Fibronectin (FN) is one of the important ECM-glycol- 
proteins which binds with Integrin. FN is also overexpressed in breast cancer [17]. Cell attachment to FN increases MMP-9 secretion in normal and tumor cell models [13-19]. These studies propose cell adhesion to FN may induce MMP-9 expression which finally facilitate cellular activities like migration, invasion. But the detail molecular framework underlying these signaling need some input. It has been also reported that FN induce FAK signaling in lung cancer cell line or mice model $[9,10,20]$. Some groups have shown involvement of FAK in MMP-2 or MMP-9 expression, secretion and activity [21,22]. Different signaling molecules like PI3K or ERK have been reported to participate in FAK signaling. FAK physically associate with PI3K or ERK and modulate their activity $[23,24]$. These molecules are also reported to participate in FAK-mediated MMP-9 expression and activity in models like gastric carcinoma, or chondrosarcoma cells $[8,9]$. Matrix metalloproteinases (MMPs) have been reported to be inhibited by vitamin A and its analogues including all-trans retinoic acid (ATRA), a major green tea polyphenol Epigallocatechin-3-gallate (EGCG) and Curcumin.

In this communication we report a role of FAK in FNmediated human breast cancer cell migration involving regulation of MMP-9 expression and activity. We have shown involvement of Integrin $\alpha 5 \beta 1$, PI3K and ERK in this signaling pathway. Moreover, we have shown that some natural compounds may be used to regulate FAK expression and thereby MMP-9 expression-activity and cell migration.

\section{MATERIALS}

Leibovitz's L-15 Medium, fetal bovine serum (FBS) were purchased from GIBCO ${ }^{\mathrm{TM}}$ - Invitrogen, Carlsbad, CA. Fibronectin (440 kDa), Protease Inhibitor Cocktail Tablets (complete, mini, EDTA-free, Cat No. 11836170 001), Protein $G$ agarose were purchased from Roche, Germany. Gelatin Sepharose 4B beads was purchased from GE Healthcare Bio-Sciences AB, Uppsala, Sweden. All primary antibodies (monoclonal and polyclonal), seconddary antibodies (FITC and HRP), FAK SiRNA and negative control SiRNA were purchased from Santa Cruz Biotechnologies, Santa Cruz, CA. USA. SYBR Green JumpStartTM Taq Readymix TM was purchased from SigmaAldrich, St. Louis, MO, USA. Primers (FAK, MMP-9, TIMP-1 and G3PDH) were synthesized by Operon, Germany. RNAqueous 4 PCR (Total RNA isolation kit) and Retroscript (RT-PCR Kit) were purchased from Ambion, Austin, TX, USA. ERK inhibitor (PD 98059), PI-3K inhibitor (LY 294002) were purchased from Promega, Madison, WI. LipofectamineTM 2000 was purchased from Invitrogen, Life Technologies (USA). SuperSignal West Pico Chemiluminescent Substrate kit was purchased from
Pierce, Thermo Fisher Scientific Inc. Rockford, USA). Alltrans Retinoic Acid (ATRA), Curcumin and EGCG was obtained from Sigma-Aldrich, USA.

\section{METHODS}

\subsection{Cell Culture}

MDA-MB-231 (human breast cancer cell line) was obtained from National Centre for Cell Sciences (NCCS), Pune, India. The cells were grown and maintained in Leibovitz's L-15 Medium containing $10 \%$ FBS in a $5 \% \mathrm{CO}_{2}$ incubator at $37^{\circ} \mathrm{C}$. All experiments with MDA-MB-231 were performed at early passages of the cell line.

\subsection{Western Blot}

MDA-MB-231 $(300,000$ cells $/ \mathrm{ml})$ cells were grown in SFCM with treatment as required in the experimental condition. Then the cells were washed with ice cold PBS and were scraped into lysis buffer (50 mM Tris, $\mathrm{pH} 7.5,150$ $\mathrm{mM} \mathrm{NaCl}, 1 \% \mathrm{NP} 40,0.1 \%$ SDS, $0.5 \%$ Deoxycholate, Protease inhibitor cocktail tablets (following manufacturer protocol), $1 \mathrm{mM}$ sodium orthovanadate and $1 \mathrm{mM}$ Sodium fluoride) on ice and clarified by centrifugation. Protein concentrations were determined using a Lowry method. The samples were then subjected to electrophoresis on SDS-PAGE and the proteins were transferred onto PVDF membrane (Millipore) by Western blot. Nonspecific binding sites on the membrane were pre-blocked in $4 \%$ BSA. Blots were incubated with anti-FAK, anti-pFAK (Tyr397), anti-PI3K, anti-pPI3K, anti-ERK, anti-pERK, anti-MMP-9 or anti-Paxillin (Santa Cruz) antibodies. Following incubation in horseradish peroxidase (HRP)-conjugated secondary, detection was performed with the Super Signal West Pico Chemiluminescent Substrate kit (Pierce, USA) following the manufacturer's protocol. All blots were reprobed with anti $\beta$-tubulin antibody as internal loading control.

\subsection{Immunoprecipitation}

MDA-MB-231 (300,000 cells $/ \mathrm{ml})$ cells were allowed to grow without or with Fibronectin $(20 \mu \mathrm{g} / \mathrm{ml})$ for $2 \mathrm{hr}$. in SFCM. For Immunoprecipitation cells were lysed with NP40 buffer (50 mM Tris, $150 \mathrm{mM} \mathrm{NaCl}, 1 \% \mathrm{NP} 40$, pH 8 , Protease inhibitor cocktail tablets, $1 \mathrm{mM}$ sodium Orthovanadate and $1 \mathrm{mM}$ Sodium fluoride). Preclearing of lysate was done by incubation with Protein G agarose and anti-human IgG at $4^{\circ} \mathrm{C}$ using for $1 \mathrm{hr}$, followed by protein estimation by Lowry method. Immunoprecipitation was performed from $100 \mu \mathrm{g}$ of protein with $1 \mu \mathrm{g}$ of anti-integrin $\alpha 5$ (H-104) sc10729 or anti FAK (A-17): sc 557 antibody (Santa Cruz Biotechnology, USA) followed by precipitation with Protein-G-Agarose for $2 \mathrm{hr}$ at $4^{\circ} \mathrm{C}$, then the beads were washed with NP40 buffer (without 
Protease inhibitor cocktail, sodium orthovanadate and sodium fluoride). The samples were prepared for SDS-PAGE with the addition of Laemmli buffer and elution at $100^{\circ} \mathrm{C}$ for $4 \mathrm{~min}$. Western blotting was performed as described.

\subsection{Gelatin Zymography}

MDA-MB-231 cells $(300,000$ cells $/ \mathrm{ml})$ were grown in absence and presence of FAK SiRNA in required concentrations and time periods in serum free culture medium (SFCM). MDA-MB-231 cells (300,000 cells/ml) were grown in presence of $\mathrm{FN}(20 \mu \mathrm{g} / \mathrm{ml})$ for 2 hours and then were kept with or without $\alpha 5$ antibody for an additional 1 hour. After either of these treatments, Gelatin Zymography was performed using a 7.5\% SDS-PAGE (sodium dodecyl sulfate polyacrylamide gel electrophoresis) co-polymerized with $0.1 \%$ gelatin as described in earlier report [25].

\subsection{Inhibitor Assay}

MDA-MB-231 cells (300,000 cells/ml) were grown in absence (control) and presence of FN $(20 \mu \mathrm{g} / \mathrm{ml})$ for $2 \mathrm{hr}$ after treatment with ERK inhibitor (PD 98059) $(50 \mu \mathrm{M})$, PI-3K inhibitor (LY 294002) $(20 \mu \mathrm{M})$ for 1 hour in SFCM. The SFCM was collected and Zymography was performed as described.

\subsection{Immunocytochemistry}

MDA-MB-231 (300,000 cells/ml) cells were allowed to grow on surface coated or not coated (Control) with Fibronectin $(20 \mu \mathrm{g} / \mathrm{ml} \mathrm{SFCM})$ upto $2 \mathrm{hr}$ at $37^{\circ} \mathrm{C}$ in a $\mathrm{CO}_{2}$ incubator. The coverslips were then washed in PBS, fixed with $3.5 \%$ formaldehyde, treated with $0.5 \%$ Triton-X 100 and nonspecific sites were blocked with 1\% BSA. The cells were then incubated with anti-FAK primary antibody (1:1000 dilution) for overnight at $4^{\circ} \mathrm{C}$ followed by wash and incubation with FITC-coupled second anti-body (1:1000 dilution) at $37^{\circ} \mathrm{C}$ for $1.5 \mathrm{hr}$ in a humidified chamber. After washing with PBS, the coverslips were mounted with glycerol on glass slides and observed under a fluorescence microscope (Leica).

\subsection{Quantitative Real-Time RT-PCR}

RNA was extracted from MDA-MB-231 cells $\left(1 \times 10^{6}\right.$ cells $/ \mathrm{ml}$ ) either grown in absence (Control) or in presence of Fibronectin $(20 \mu \mathrm{g} / \mathrm{ml})$ for $1 \mathrm{hr}$ and $2 \mathrm{hr}$; or grown in absence or presence of FAK SiRNA and control SiRNA prior to treatment with Fibronectin $(20 \mu \mathrm{g} / \mathrm{ml})$ for $2 \mathrm{hr}$. Cells were washed in PBS and total RNA was extracted (RNAqueous, Ambion, USA) as previously discussed [26]. Real-Time quantitative RT-PCR using relative quantitation by the comparative $\mathrm{C}_{\mathrm{T}}$ method was used to deter- mine mRNA expression. $2 \mu$ of cDNA was subjected to Real-Time quantitative RT-PCR using SYBR Green as a fluorescent reporter. The specific gene primers (MMP-9, FAK, TIMP-1 and the internal control gene G3PDH) were amplified in separate reaction tubes. Threshold cycle number $\left(C_{T}\right)$, of triplicate reactions, was determined using the ABI-7500 (ABI-7500, Foster City, CA USA) software and the mean $\mathrm{C}_{\mathrm{T}}$ of triplicate reactions was determined using the protocol previously described [27]. The calibrator used in our experiments is the control MDA-MB-231 cells and the samples are Fibronectin treated $(20 \mu \mathrm{g} / \mathrm{ml}, 2$ hr) MDA-MB-231 cells. The $\Delta \mathrm{C}_{\mathrm{T}}$ value being inversely proportional to the mRNA expression of the samples. No primer dimers were obtained for either the target genes or G3PDH as assessed by melt curve analysis. The specificity of the products was also confirmed by melt curve analysis. The reaction conditions and the primer sequences are given below. The PCR cycles in all cases were started with Taq activation at $94^{\circ} \mathrm{C}$ for 5 min and followed by final extension of $72^{\circ} \mathrm{C}$ for $7 \mathrm{~min}$. Primer sequences, PCR cycles and conditions:

hFAK: 5'-GCGCTGGCTGGAAAAAGAGGAA-3' (forward) 5'-TCGGTGGGTGCTGGCTGGTAGG-3' (reverse);

hMMP-9: 5'-CGCTACCACCTCGAACTTTG-3'(forward) 5'-GCCATTCACGTCGTCCTTAT-3'-(reverse);

hTIMP-1: 5'-CACCCACAGACGGCCTTCTGC-3'(forward) 5'-AGTGTAGGTCTTGGTGAAGCC-3'-(reverse);

GAPDH: 5'-CGGAGTCAACGGATTTGGTCGTAT3'(forward) 5'-AGCCTTCTCCATGGTGGTGAAGAC3'(reverse).

RT-PCR was carried out using Two Step RT-PCR kit (Retroscript Ambion, USA). Conditions used for PCR consisted of 40 cycles for FAK, MMP-9, and TIMP-1 at $94^{\circ} \mathrm{C}$ for $30 \mathrm{sec}, 58^{\circ} \mathrm{C}$ for $30 \mathrm{sec}$ and $72^{\circ} \mathrm{C}$ for $30 \mathrm{sec}$ with a final incubation at $72^{\circ} \mathrm{C}$ for $7 \mathrm{~min}$ in DNA thermal cycler.

\subsection{Focal Adhesion Kinase Small Interfering RNA (SiRNA) Treatment}

Human breast cancer cell line MDA-MB-231 were seeded in $35 \mathrm{~mm}$ dishes and grown to $60 \%$ confluence. For the transfection process, FAK SiRNA and negative control SiRNA were transfected using LipofectamineTM 2000 following the manufacturer's protocol. The transfection agent (LipofectamineTM 2000) was incubated with serum-free culture medium for 10 mins at room temperature. Subsequently, respective SiRNA (FAK SiRNA (h), sense-GCAUGUGGCCUGCUAUGG; antisense-CCAUAGCAGGCCACAUGC) mixed with serum-free cul- 
ture medium was added to it and incubated at room temperature for additional $15 \mathrm{~min}$. The mixtures were then diluted in serum free culture medium and added to each dish so that the final concentration of the SiRNA in each plate was $100 \mathrm{nM}$. The mixture was overlaid on the cells in full media without serum and without antibiotic and incubated at $37^{\circ} \mathrm{C}$ in the presence of $5 \% \mathrm{CO}_{2}$. After $24 \mathrm{hr}$, the transfection mixture was replaced with fresh media supplemented with 10\% FBS and antibiotic and the transfected cells allowed growing for another $48 \mathrm{hr}$. Cells were exposed to FN for $2 \mathrm{hr}$ and later collected for western blot, gelatin Zymography and real-time RT-PCR assays.

\subsection{Wound-Healing Assay}

Cells were kept in SFCM for $1 \mathrm{~h}$ with thrice change and were exposed or not exposed to FN $(20 \mu \mathrm{g} / \mathrm{ml})$ in culture dish and grown for $2 \mathrm{hr}$. The monolayer was scratched with sterile tip, washing $3 \times$ with SFCM. The cells were maintained in fresh SFCM and cell migration was observed under microscope and photographed at different time points $(0,12$, and $24 \mathrm{hr})$ [28].

\subsection{Treatment of the Natural Products}

MDA-MB-231 cells $(300,000$ cells $/ \mathrm{ml})$ were treated with $20 \mu \mathrm{M}$ of ATRA, Curcumin and EGCG separately for 24 hr [29-31]. Control cells were treated with equal concentration of DMSO. In case of experiments with fibronectin treatment, cell were grown in absence or presence of $20 \mu \mathrm{g} / \mathrm{ml}$ fibronectin for $2 \mathrm{hr}$. after the treatment of the natural products.

\subsection{Quantification of the Results}

Bands of Zymography, Western blots and RT-PCR were quantitated using Image J Launcher (version 1.4.3.67).

\section{RESULTS}

\subsection{Culture of MDA-MB-231 Cells on FN Coated Surface Promotes FAK Expression, Activation and Processing}

Western Blot analysis showed increased expression, phosphorylation and processing of FAK in time dependent manner when cells were exposed to FN for upto $2 \mathrm{hr}$, compared to the FN-untreated control cells. The expression, phosphorylation and cleavage of FAK were found to be increased from $30 \mathrm{~min}$ to $2 \mathrm{hr}$ (Figure 1(a)).

\subsection{Real-Time PCR of FAK, MMP-9 and TIMP-1 in FN Treated and Untreated MDA-MB-231 Cells}

MDA-MB-231 treated with FN for $1 \mathrm{hr}$ and $2 \mathrm{hr}$ clearly shows that FAK and MMP-9 expression was up-regulated 4 fold whereas TIMP-1 message decreased 2 folds. GAPDH gene expression was used as standard internal control to normalize RNA integrity and equal loading (Figure 1(b)).

\subsection{Culture of MDA-MB-231 Cells on FN Coated Surface Shows Localization of FAK in Adhesion Plaques}

When MDA-MB-231 cells were grown on Fibronectin coated surface for $30 \mathrm{~min}, 1 \mathrm{hr}$ and $2 \mathrm{hr}$, FAK (upper panel) and p-FAK (lower panel) were found to be localized at adhesion plaques. It became increasingly distinct from $30 \mathrm{~min}$ to $2 \mathrm{hr}$. However these punctuate fashion was not observed in cells without FN treatment (Figure 1(c)).

\subsection{Association of FAK with $\alpha 5 \beta 1$ Integrin, Paxillin and Actin Increases in FN-Treated MDA-MB-231 Cells}

$\alpha 5 \beta 1$ integrin was immunoprecipitated with $\alpha 5$ monoclonal antibody from cell extract. With this immunoprecipitate a blot was developed with anti-FAK antibody and it was observed that FAK was associated with $\alpha 5 \beta 1$. In another set of experiment Paxillin (upper panel) \& Actin (lower panel) was found to be immunoprecipitated with FAK, upon immunoprecipitation with anti-FAK antibody. The associations were increased several folds when cells were exposed to FN than the untreated control cells (Figure 2(a)).

\subsection{Masking of $\alpha 5 \beta 1$ Integrin with $\alpha 5$ Monoclonal Antibody Decreased FAK Expression, Phosphorylation and MMP-9 Activity}

Western Blot analysis indicates when $\alpha 5$ integrin was masked by treating cells with anti- $\alpha 5$-integrin antibody for $1 \mathrm{hr}$ prior to FN treatment, the amount of FAK expression and phosphorylation became as good as FN untreated cells (Figure 2(b)). The comparative zymogram shows MMP-9 activity was appreciably reduced when $\alpha 5-$ integrin was blocked with anti- $\alpha 5$-integrin antibody prior to FN treatment (Figure 2(c)).

\subsection{Effect of FAK Silencing on MMP-9 and FAK}

Appreciable decrease in FAK and MMP-9 mRNA expression was observed by Real-Time PCR (Figure 3(a)) when FAK was silenced followed by FN treatment. The decrease was also reflected in protein level when subjected to Western Blot analysis (Figure 3(b)). Again MMP-9 gelatinolytic activity by zymography (Figure 3(c)) was also 

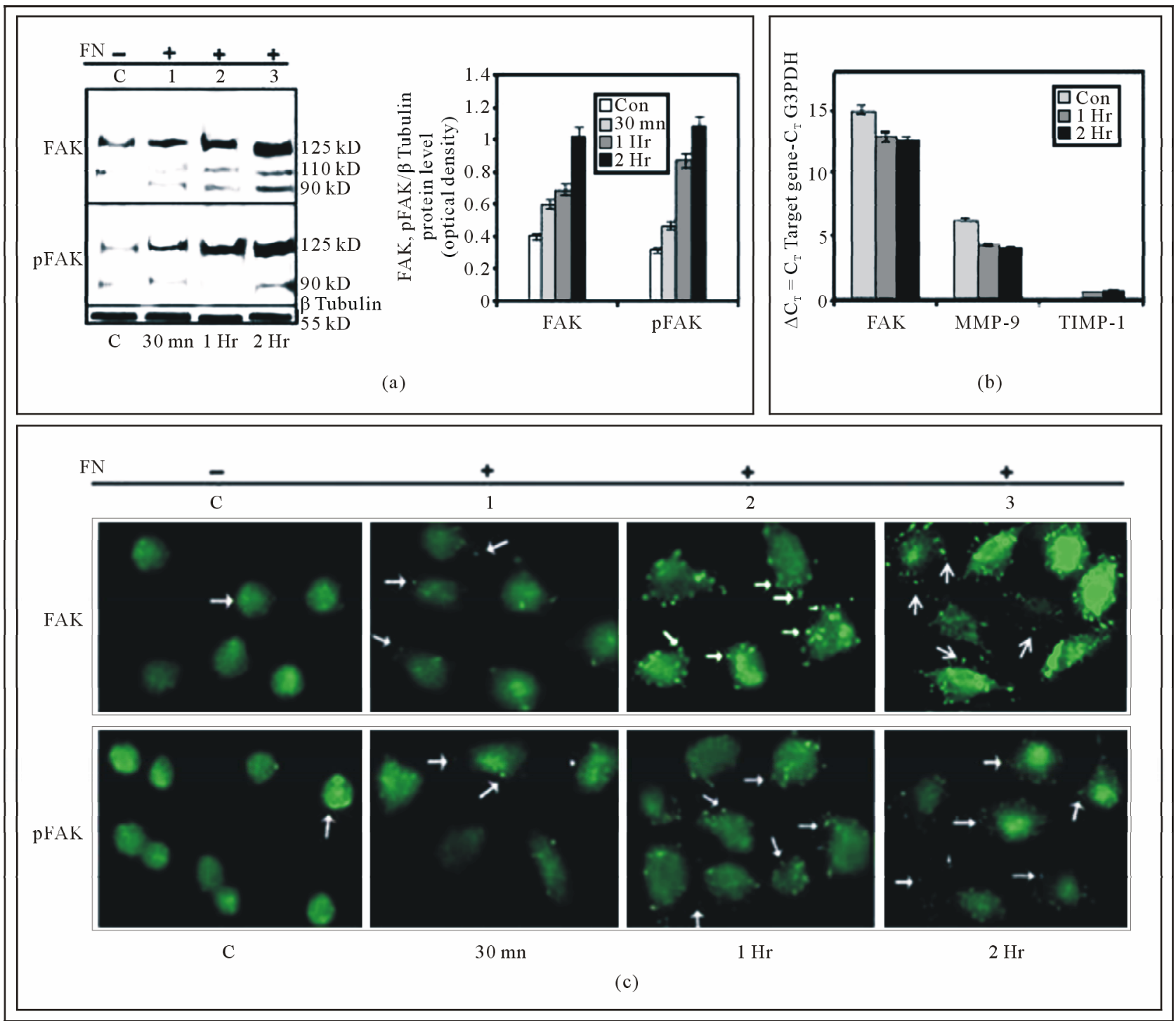

Figure 1. (a) Effect of cell-ECM interaction on expression and phosphorylation of FAK in MDA-MB-231 cells: MDA-MB-231 cells $(300,000$ cells $/ \mathrm{ml})$ were grown in SFCM in absence (C), in presence of $20 \mu \mathrm{g} / \mathrm{ml} \mathrm{FN}$ coated for $30 \mathrm{mins}(1), 1 \mathrm{hr}(2)$ and $2 \mathrm{hr}$ (3) The cells were collected; extracted and equal protein $(100 \mu \mathrm{g})$ was subjected to western blot analysis with anti-FAK (upper panel) and anti-p-FAK (lower panel) antibody. $\beta$-tubulin was used as internal control and done in parallel to all the blots. The accompanying graphs represent the comparative densitometric/quantitative analysis of the band intensities; (b) mRNA expression of FAK, MMP-9 and TIMP-1 assayed by Quantitative Real-Time RT-PCR: MDA-MB-231 cells (300,000 cells/ml) were grown in absence (C) and in presence $20 \mu \mathrm{g} / \mathrm{ml} \mathrm{FN}$ coated for $30 \mathrm{~min}, 1 \mathrm{hr}$ and $2 \mathrm{hr}$ in SFCM. Total RNA was extracted from control and experimental MDAMB-231 cells $\left(1 \times 10^{6}\right.$ cells). 2 steps RT-PCR was done with equal amounts of total RNA. $2 \mu$ of cDNA was subjected to Real-Time quantitative RT-PCR with SYBR Green as a fluorescent reporter. Relative levels of expression of MMP-9, FAK and TIMP-1 and the control G3PDH in control and experimental sets was measured by quantitative real time RT-PCR by calculating the $\mathrm{C}_{\mathrm{T}}$ value. The calibrator used in our experiments is the control FN untreated (C) MDA-MB-231 cells and the samples are the $1 \mathrm{hr}(1)$ and $2 \mathrm{hr}(2)$ FN-treated cells. In the given graph the $\mathrm{C}_{\mathrm{T}}$ value is inversely proportional to the mRNA expression of the samples; (c) Immunocytochemistry of FAK and p-FAK upon cell-ECM interaction: MDA-MB-231 cells were grown on coverslips in absence (C) and presence of Fibronectin $(20 \mu \mathrm{g} / \mathrm{ml}$ ) for $30 \mathrm{~min}(1), 1 \mathrm{hr}(2)$ and $2 \mathrm{hr}$ (3) Immunocytochemistry was preformed with anti-FAK (upper panel) anti-p-FAK (lower panel) antibody and then incubated with FITC-labeled respective secondary antibody. Coverslips were observed under a fluorescence microscope.

downregulated in response to FAK inhibition. Observations revealed expression of FAK, MMP-9 and MMP-9 activity were increased upon exposure of cells to FN. Whereas, treatment of cells with FAK SiRNA prior to FN-exposure appreciably downregulated FAK, MMP-9 expression and MMP-9 activity. Cells treated with control SiRNA did not show any notable change of FAK, MMP-9 expression or MMP-9 activity. 


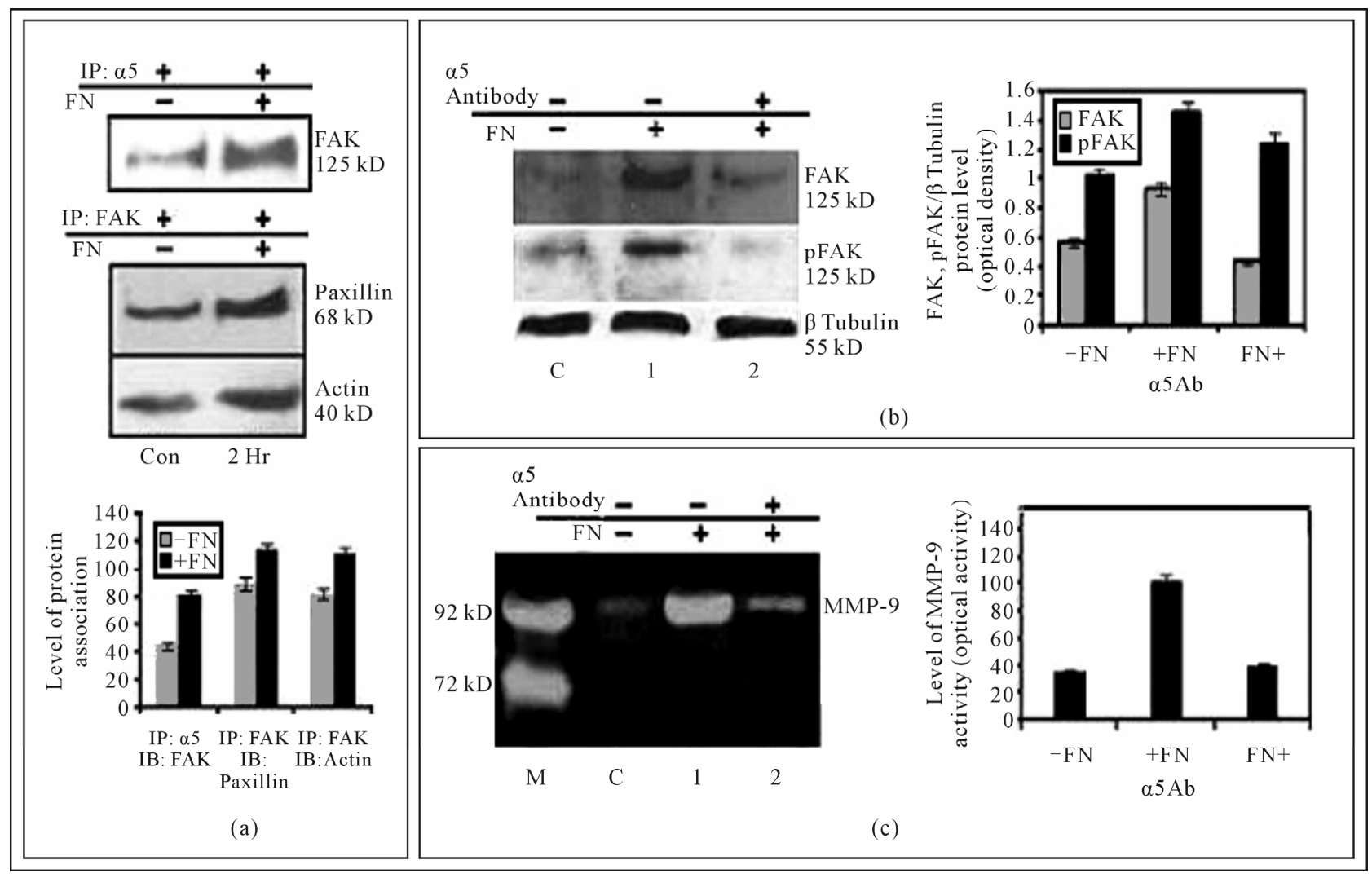

Figure 2. (a) Interaction of FAK with of integrin receptor $\alpha 5 \beta 1$, Paxillin and Actin in MDA-MB-231 cells: MDA-MB-231 cells $(300,000$ cells $/ \mathrm{ml})$ were grown in SFCM in absence (C), in presence of $20 \mu \mathrm{g} / \mathrm{ml} \mathrm{FN} \mathrm{coated} \mathrm{for} 2$ hours $(2 \mathrm{hr})$. The cells were collected; extracted and equal protein was immunoprecipitated with anti- $\beta 1$ antibody or anti-FAK antibody and subjected to western blot analysis with anti-FAK (upper panel), anti-paxillin (middle panel) and anti-Actin antibody. The accompanying graphs represent the comparative densitometric/quantitative analysis of the band intensities; (b) Integrin $\alpha 5 \beta 1$ is involved in fibronectin-induced FAK phosphorylation (Tyr-397) and modulate MMP-9 activity: MDA-MB-231 cells $(300,000 \mathrm{cells} / \mathrm{ml})$ were grown in absence (C) or presence of fibronectin ( $20 \mu \mathrm{g} / \mathrm{ml}$ for 2 hours) (1) In other set cells were treated of $1 \mu \mathrm{g} / \mathrm{ml}$ anti- $\alpha 5$ antibody (2) for 1 hour prior to growing on $20 \mu \mathrm{g} / \mathrm{ml}$ fibronectin for 2 hours. The cells were collected; extracted and equal protein $(100 \mu \mathrm{g})$ was subjected to western blot analysis with anti-FAK and anti-p-FAK antibody. $\beta$-tubulin was used as internal control and done in parallel to the blot. The accompanying graph represents the comparative densitometric/quantitative analysis of the band intensities; (c) The SFCM of control (C), FN treated (1) and FN and $\alpha 5$ antibody treated (2) sets were collected. The culture supernatants were collected and gelatin zymography was performed by using a $7.5 \%$ SDS-PAGE co-polymerized with $0.1 \%$ gelatin. The accompanying graph represents the comparative densitometric/quantitative analysis of the band intensities.

\subsection{FAK Physically Associates with PI3K and ERK in MDA-MB-231 Cells}

From the Western Blot it was found that PI3K and ERK co-precipitate with FAK when it is immunoprecipitated with anti-FAK antibody. The association increases several folds in FN-treated cells (Figure 4(a)).

\subsection{FAK-Silencing Appreciably Downregulated the Phosphorylation of PI3K and ERK in MDA-MB-231 Cells}

Western blot analysis shows, phosphorylation of PI3K and ERK is increased a several folds when cell are exposed to FN. But the phosphorylation of PI3K and ERK was appreciably down regulated when cell were treated with FAK SiRNA prior to FN treatment. In contrary, the activity remain unaltered when cell were treated with Control SiRNA prior to FN treatment (Figure 4(b)).

\subsection{Inhibition of ERK and PI3K Downregulated MMP-9 Gelatinolytic Activity}

When MDA-MB-231 cells were treated with ERK or PI3K inhibitor prior to FN treatment, MMP-9 activity was found to be downregulated a several folds, compared to only FN treated cells (Figure 4(c)).

\subsection{Treatment of MDA-MB-231 Cells with FAK SiRNA Results in a Loss of Cell Migration}

Effect of FAK silencing on cell migration was observed in FN treated and untreated conditions. Depletion of 


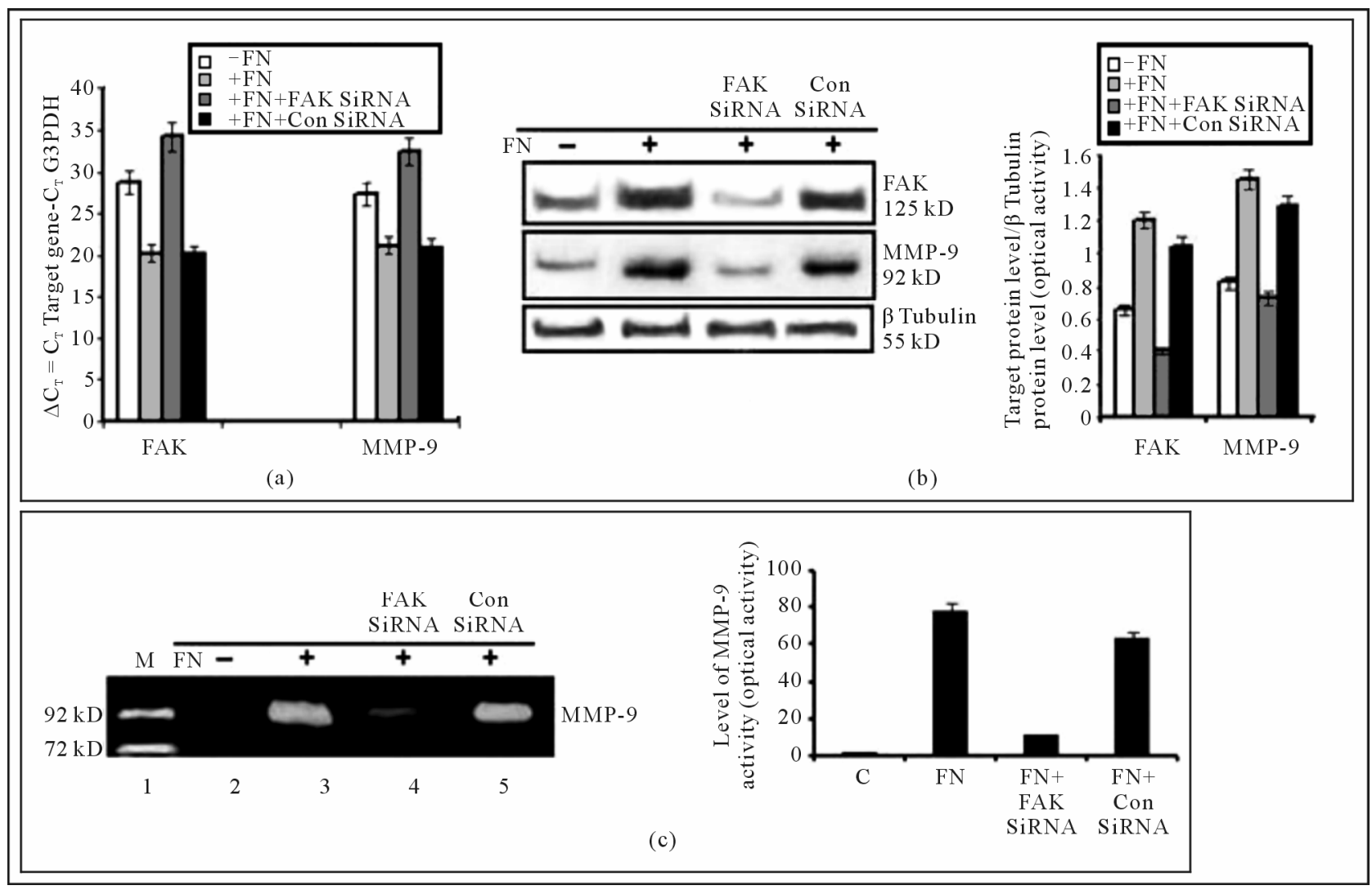

Figure 3. (a) Effect of FAK silencing on FAK and MMP-9 mRNA expression: after FAK silencing MDA-MB-231 cells were lysed and RNA was extracted. After reverse transcription level of FAK and MMP-9 expression was measured by Real time PCR. Relative levels of expression of FAK, MMP-9 and the control G3PDH in control, FN treated $(20 \mu \mathrm{g} / \mathrm{ml}$ for 2 hours) and siRNA (control siRNA and FAK siRNA) treated MDA-MB-231 cells as measured by calculating the $\mathrm{C}_{\mathrm{T}}$ value. The calibrator used in our experiments is the control untreated (-FN) MDA-MB-231 cells and the samples are the FN treated $(20 \mu \mathrm{g} / \mathrm{ml}, 2$ hours $)(+\mathrm{FN})$ and siRNA treated (+FN+ control siRNA or $+\mathrm{FN}+\mathrm{FAK}$ siRNA) MDA-MB-231 cells. In the given graph the $\mathrm{C}_{\mathrm{T}}$ value is inversely proportional to the mRNA expression of the samples; (b) Effect of FAK silencing on protein levels of FAK \& MMP-in MDA-MB-231 cells: MDA-MB-231 cells were grown in SFCM for 24 hours, transfected with control SiRNA (lane 3) and FAK siRNA (lane 2) (100 nM each) for $48 \mathrm{hr}$ before treating the cells with $20 \mu \mathrm{g} / \mathrm{ml} \mathrm{FN}$ coated for 2 hours. Control cells were untreated with FN (C), where only FN treated cell are in lane 1 . The cells were collected; extracted and equal protein $(100 \mu \mathrm{g})$ was subjected to western blot analysis with anti-FAK (upper panel), anti-MMP-9 (lower panel) antibody. $\beta$-tubulin was used as internal control and done in parallel to the blots. The accompanying graphs represent the comparative densitometric/quantitative analysis of the band intensities; (c) Effect of FAK silncing on MMP-9 activity: MDA-MB-231 cells were grown in SFCM for $24 \mathrm{hr}$, transfected with control (lane 5) and FAK SiRNA (lane 4) (100 $\mathrm{nM}$ each) for $48 \mathrm{hr}$ before treating the cells with $20 \mu \mathrm{g} / \mathrm{ml} \mathrm{FN}$ coated for 2 hours. The culture supernatants were collected and gelatin zymography was performed by using a $7.5 \%$ SDS-PAGE co-polymerized with $0.1 \%$ gelatin.

FAK was found to retard cell migration even after $24 \mathrm{hr}$ of making wound compared to the control cells (Figure $5)$.

\subsection{Treatment of MDA-MB-231 Breast Cancer Cells with Some Natural Products Changes Pattern of Cell-Attachment and Cell Morphology}

When MDA-MB-231 cells were treated with Curcumin $(20 \mu \mathrm{M})$, ATRA $(20 \mu \mathrm{M})$ and EGCG $(20 \mu \mathrm{M})$, the cell were found to become constricted, spindle shaped and/or roundish with stretched attachment after $24 \mathrm{hr}$, compared to the untreated cells (Figure 6(a)).

\subsection{Treatment of the Natural Products Downregulate FAK Expression}

Western blot analysis showed that expression of FAK was downregulated upon treatment of MDA-MB-231 cells with Curcumin $(20 \mu \mathrm{M})$, ATRA $(20 \mu \mathrm{M})$ and EGCG $(20$ $\mu \mathrm{M})$ for $24 \mathrm{hr}$. Upon treatment with Curcumin, ATRA and EGCG, FAK expression was to found to be downregulated by $2.14,1.68,1.81$ folds respectively. $\beta$-Tubulin was taken as loading control (Figure 6(b)).

\subsection{Treatment of the Natural Products Downregulate MMP-9 Activity}

When MDA-MB-231 cells were treated with Curcumin 


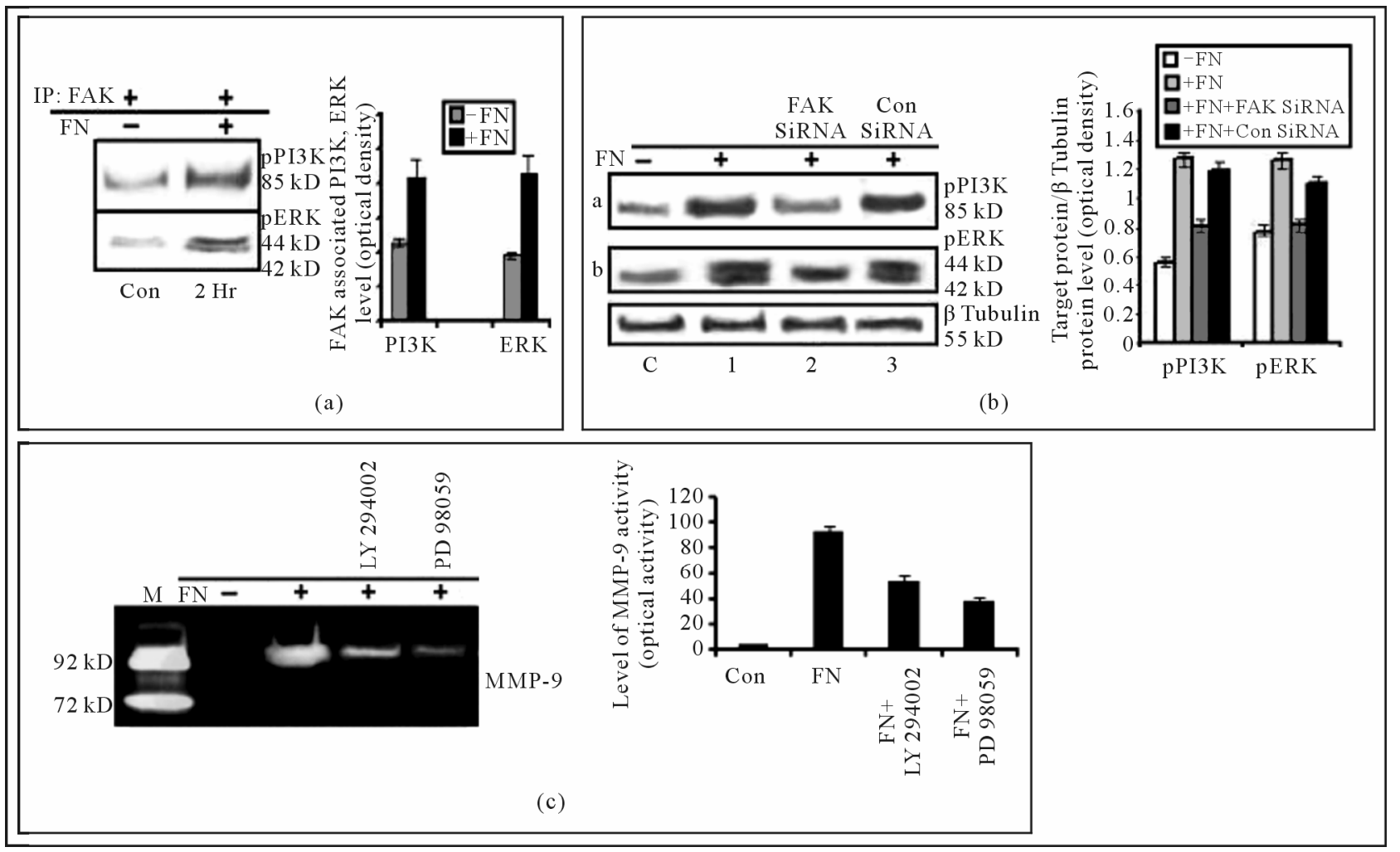

Figure 4. (a) Effect of FN treatment on the association of FAK with PI-3K and ERK in MDA-MB-231 cells: MDA-MB-231 cells $(300,000$ cells $/ \mathrm{ml})$ were grown in SFCM in absence $(\mathrm{C})$, in presence of $20 \mu \mathrm{g} / \mathrm{ml} \mathrm{FN}$ coated for 2 hours $(2 \mathrm{hr})$. The cells were collected; extracted and equal protein was immunoprecipitated with anti-FAK antibody and subjected to western blot analysis with anti-PI-3K (upper panel) and anti-ERK (lower panel) antibody; (b) Effect of FAK silencing on PI3K and ERK: MDA-MB-231 cells were grown in SFCM for 24 hours, transfected with control SiRNA (lane 3) and FAK siRNA (lane 2) (100 nM each) for $48 \mathrm{hr}$ before treating the cells with $20 \mu \mathrm{g} / \mathrm{ml} \mathrm{FN} \mathrm{coated} \mathrm{for} 2$ hours. Control cells were untreated with FN (C), where only FN treated cell are in lane 1. The cells were collected; extracted and equal protein $(100 \mu \mathrm{g})$ was subjected to western blot analysis with anti-anti-p-PI3K (panel a) and p-ERK1/2 (panel b) antibody. $\beta$-tubulin was used as internal control and done in parallel to the blots; (c) Involvement of PI3K and ERK in FN induced MMP-9 activity in MDA-MB-231 cells: MDA-MB-231 cells (300,000 cells/ml) were grown in absence (lane Con) and presence of FN (lane FN). Again cells were also grown in PI-3K inhibitor (LY 294002) (lane 4), ERK inhibitor (PD 98059) (lane 5) at a concentration of $50 \mu \mathrm{M}$ for 1 hour in SFCM prior to FN treatment. The culture supernatants were collected and gelatin zymography was performed by using $7.5 \%$ SDS-PAGE co-polymerized with $0.1 \%$ gelatin. The accompanying graph represents the comparative densitometric/quantitative analysis of the band intensities.

$(20 \mu \mathrm{M})$, ATRA $(20 \mu \mathrm{M})$ and EGCG $(20 \mu \mathrm{M})$ for $24 \mathrm{hr}$, MMP-9 activity was found to be downregulated by 49.32 , 4.81, 7.33 folds (Figure 6(c)).

\subsection{Migration of MDA-MB-231 Cells Are Decreased upon Treatment of the Natural Products}

Cell migration assay demonstrated that the migration of MDA-MB-231 cells was accelerated when the cells were exposed to Fibronectin (FN) for $2 \mathrm{hr}$. But when the cells were treated with Curcumin $(20 \mu \mathrm{M})$, ATRA $(20 \mu \mathrm{M})$ and EGCG $(20 \mu \mathrm{M})$ for $24 \mathrm{hr}$ prior to exposure to FN, cell migration were drastically decreased (Figure 7).

\section{DISCUSSION}

Overexpression and increased phosphorylation of Focal
Adhesion Kinase (FAK) in human breast cancer tissue have been reported by several groups. Studies have shown that increase of FAK have relation with progression of several cancers including breast cancer [32-35]. In invitro studies, depletion of FAK shows its importance in a number of cellular activities like cell migration and cytoskeletal organization, as well as cell survival and cell cycle progression [14,36-38]. An important ECM glycoprotein Fibronectin (FN) plays crucial role in regulating activity of FAK both in physiological and pathological conditions. A number of groups have reported FN-mediated FAK activation and its participation in transducing the signal from ECM to cell interior [10,39]. Involvement FAK in regulation of MMP-9 has also been reported in different cell type [16,22]. Our lab has shown induction of MMP-9 expression and activity in FN induced MDA-MB-231 [40]. In this communication we have 


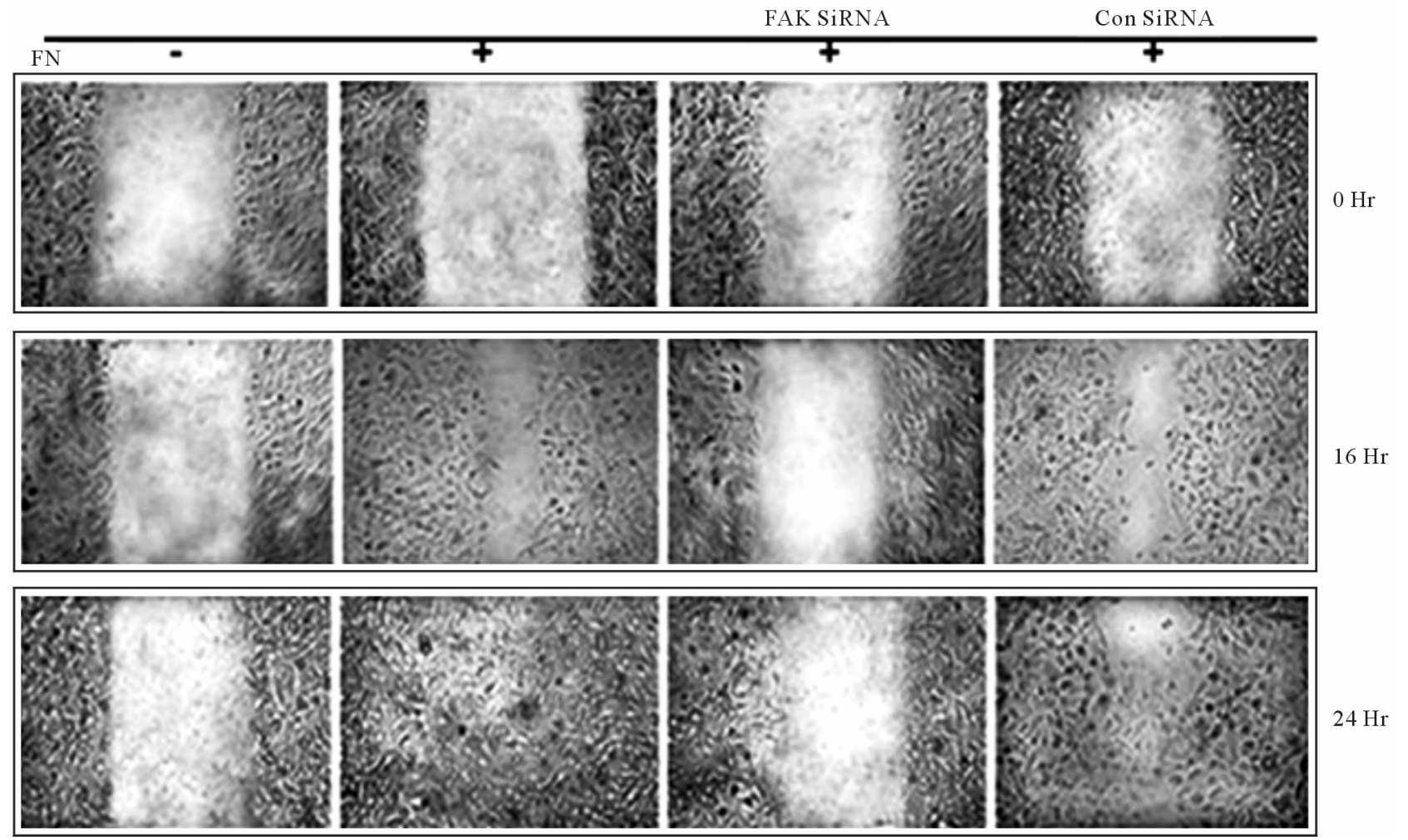

Figure 5. Inhibition of FAK decreases cell migration: FAK SiRNA or Control SiRNA treated or untreated MDA-MB-231 cells were cultured in a monolayer in absence (-FN) and presence (+FN) of fibronectin $(20 \mathrm{mg} / \mathrm{ml})$ for $2 \mathrm{~h}$. The monolayer was scratched with a sterile pipette tip, followed by washing thrice with SFCM to remove cellular debris. The cells were maintained in fresh SFCM and cell migration was observed by microscopy and documented by photography at $0 \mathrm{hr}, 16 \mathrm{hr}$ and $24 \mathrm{hr}$.

used FN-treated MDA-MB-231 model to study the participation of FAK in regulation of MMP-9 and thereby cell migration.

Our current findings clearly indicate FAK plays the pivotal role in regulation of cell migration in $\mathrm{FN}$ induced MDA-MB-231 breast cancer cells. Consistent with earlier reports we found an increased expression and phosphorylation (Tyr 397) of FAK, increased expression and activity of MMP-9, and reduced expression of TIMP-1 in this model [40]. So, FN induces FAK and MMP-9 but negatively regulate the inhibitor of MMP-9. The importance of FAK in Fibronectin-mediated cell migration was supported by our data showing that these processes are appreciably inhibited after the depletion of FAK by specific SiRNA.

Induction of FAK and signaling events at downstream of it that affect cell migration is complex. For example, after binding of FN-integrin interaction FAK is activated by autophosphorylation at Tyr 397. This event initiates the signaling, which leads to interaction of FAK with several proteins and its phosphorylation at other sites. The $\mathrm{SH} 2$ domain of $\mathrm{p} 85$ subunit of PI3K interacts with FAK at Tyr397 [18,41]. In addition, activation of FAK induces ERK activation [1,42]. Again reports show in different systems that FAK regulates MMP-9 activity which is an important modulator of cell migration by degradation of ECM [16].

To better understand the mechanism by which FAK regulates Fibronectin-induced cell migration, we examined the expression and activity of MMP-9 which is the downstream target of integrin receptors, responsible for ECM degradation. Upon treatment of MDA-MB-231 cells with the FAK SiRNA; we found reduced activation of FAK as evidenced by reduced phosphorylation at its Tyr397 residues. This inhibition showed the reduction of MMP-9 expression and activity. Thus, it seems that FAK promotes MDA-MB-231 breast cancer cell migration through modulation of MMP-9.

We examined signaling involved in FN induced FAK activation. Consistent with earlier reports in other cell types [43]; we found association of FAK with integrin $\alpha 5 \beta 1$, which is enhanced upon FN treatment. The study was further supported by the observation that downregulation of FAK expression and phosphorylation at Tyr 397 occurred after blocking the interaction of FN and integrin $\alpha 5$. This treatment also appreciably reduced MMP-9 activity. These results indicate, FN treatment induces FAKintegrin $\alpha 5 \beta 1$ association. This interaction is essential for FAK phosphorylation, which in turn triggers MMP-9 activity. Moreover, FN treatment increased localization 


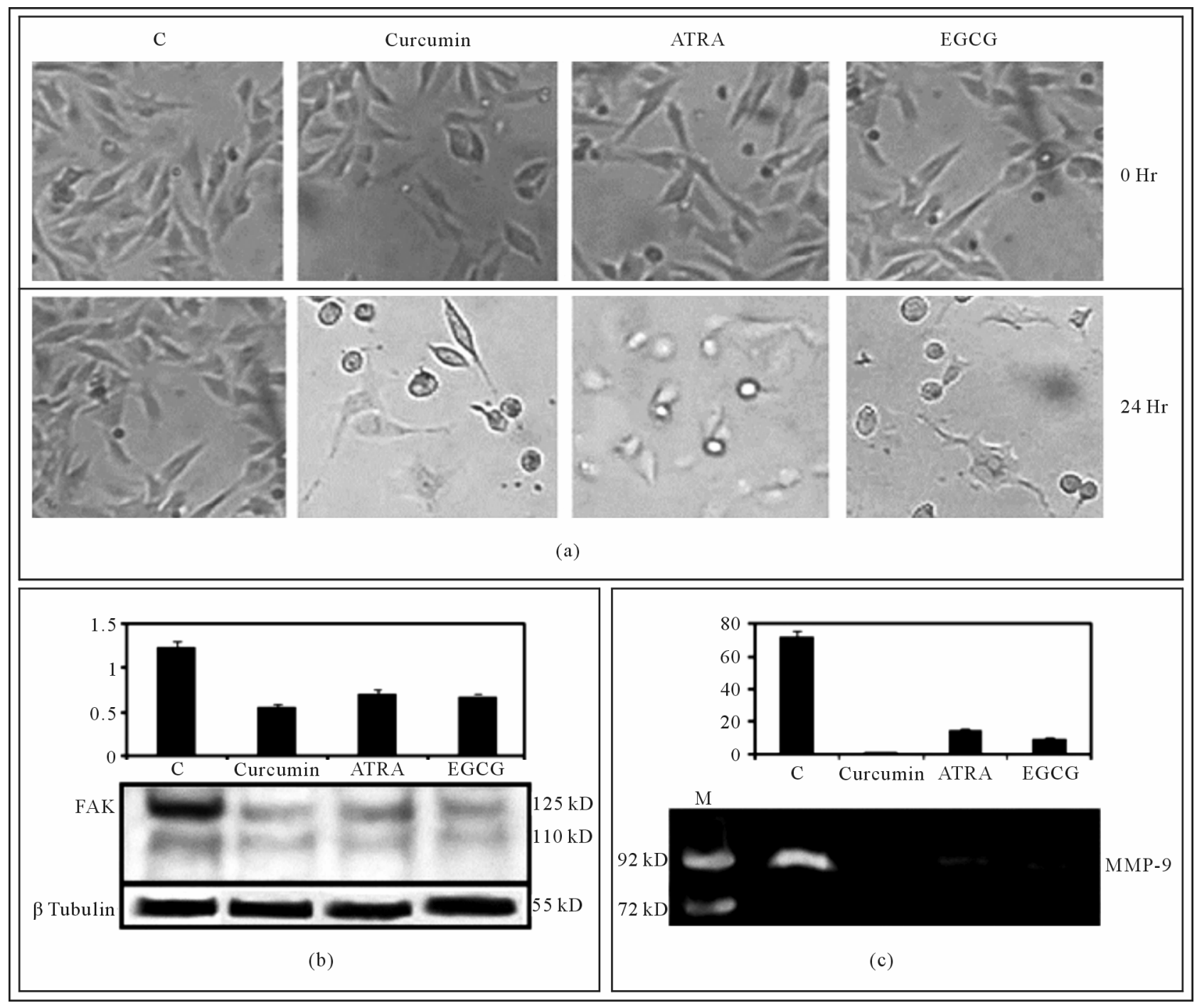

Figure 6. Effect of the Natural products on cell attachment, FAK expression and MMP-9 activity: MDA-MB-231 cells were grown for overnight and allowed to attach properly in presence of $10 \%$ serum. Cells were washed thrice with SFCM to remove serum. Then the cells were grown in SFCM in absence (C) or in presence of natural products (Curcumin, ATRA, EGCG) for $24 \mathrm{hr}$. (a) Cell morphology was observed; (b) Cells were harvested and protein was extracted. Equal amount (100 $\mu \mathrm{g} / \mathrm{well})$ was resolved and western blot was developed with anti-FAK antibody (1:2000 dilution). $\beta$-tubulin was used as internal control and done in parallel to the blots; (c) After the treatment SFCM was collected and gelatin zymography was performed by using 7.5\% SDS-PAGE co-polymerized with $0.1 \%$ gelatin. SFCM from HT1080 culture was run as molecular standard molecular weight marker for MMP-9.

of FAK at Focal Adhesion sites as well as its association with Paxillin and Actin. So, in response to FN treatment FAK recruited in Focal Adhesion points where it is phosphorylated after interaction with integrin $\alpha 5 \beta 1$. Paxillin is a focal adhesion protein. FAK-Paxillin association and their interaction with integrin $\beta 1$ was reported as positive modulator of cancer cell migration [43]. FAK is a modulator of Actin assembly [44] which is an important part of cytoskeletal remodeling and cell migration.

Consistent with previous report [40] we found enhanced phosphorylation of ERK and PI3K in FN-treated MDA-MB-231 breast cancer cells. The importance of FAK in the phosphorylation of these effectors was noted through their down regulated phosphorylation after the depletion of FAK with specific SiRNA. On the basis of our results, it appears that FAK promotes Fibronectinmediated signaling in MDA-MB-231 breast cancer cell through phosphorylation of ERK, PI3K.

In this model, reduction of MMP-9 activity after inhibition of ERK indicates the involvement of ERK in FN induced MMP-9 regulation. Studies in ovarian carcinoma cells have shown that FAK and ERK are important for Fibronectin stimulated invasiveness and MMP9 secretion by these cells [21]. A number of groups have suggested that activation of PI3K regulates the expression and activity of MMP-9 in various cancer cells. In a model of 

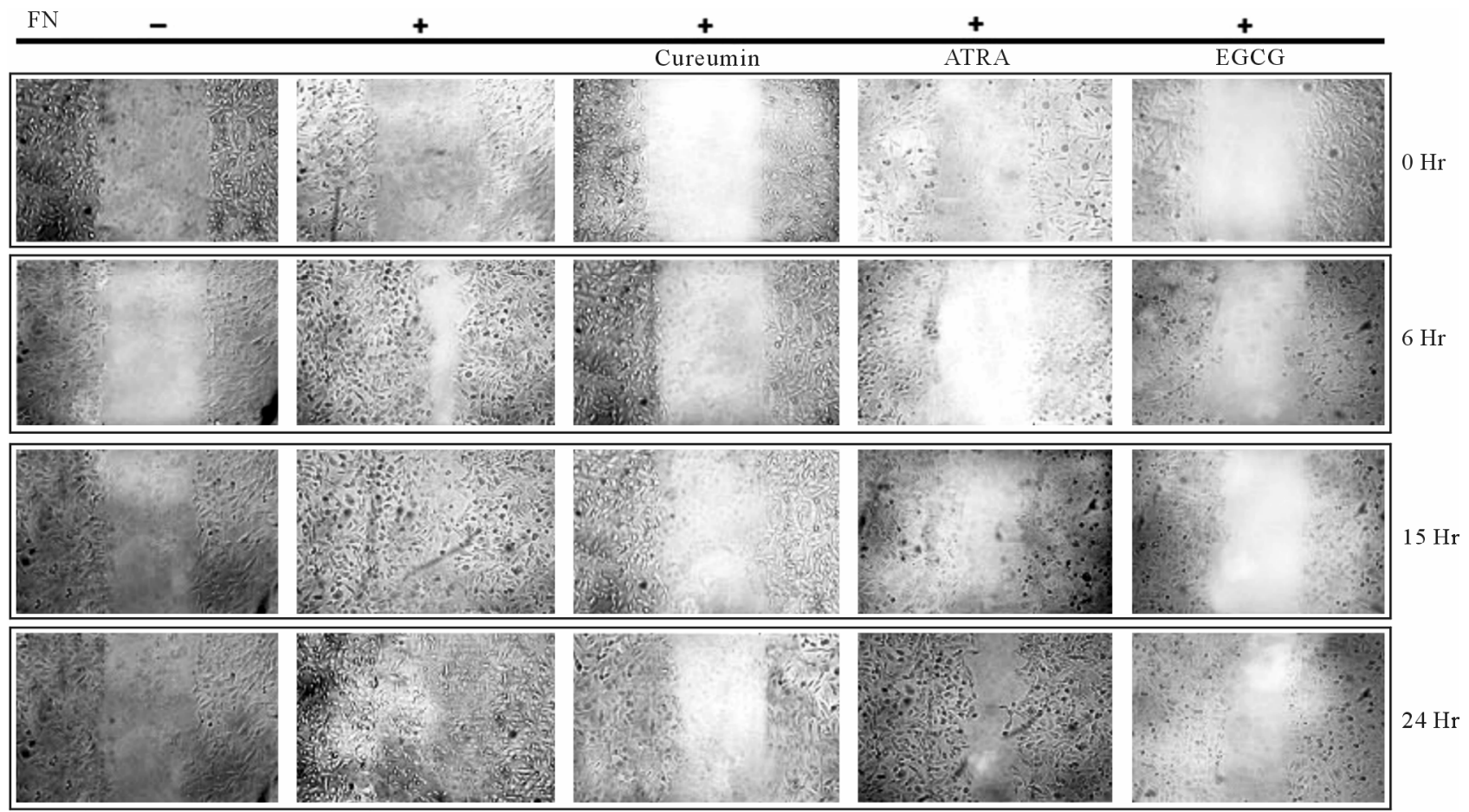

Figure 7. Effect of the natural products on cell migration: MDA-MB-231 cells were plated in such a cell density that it form confluent cell layer after growing for overnight in $10 \%$ serum. Cells were washed thrice with SFCM to remove serum. Then the cells were grown in SFCM in absence (C) or in presence of natural products (Curcumin, ATRA, EGCG) for $24 \mathrm{hr}$. Cells were grown in absence (C) or in presence FN (panel FN, Curcumin, ATRA and EGCG) for $2 \mathrm{hr}$. Scratch wound was given with sterile $200 \mu \mathrm{l}$. Cells were washed to remove the suspending cells and incubated in SFCM for $24 \mathrm{hr}$. Within this period photograph was taken after $0 \mathrm{hr}, 6 \mathrm{hr}, 15$ $\mathrm{hr}$ and $24 \mathrm{hr}$. Cell migration was compared depending the initial scratch width as marked by parallel lines.

Chinese hamster ovary (CHO) cells, Heinz et al. have shown involvement of PI3K in FAK-promoted cell migration [45]. In spite of these findings, the specific role of PI3K in controlling the cell migration, particularly in relation to FAK signaling in breast cancer has been subtle. Here, we found that PI3K associates with FAK and its phosphorylation is regulated by FAK. Inhibition of PI3K in MDA-MB-231 breast cancer cells by LY294002, showed appreciable decrease in activity of MMP-9, suggesting that $\mathrm{PI} 3 \mathrm{~K}$ is also involved in the Fibronectininduced, FAK-mediated regulation of MMP-9. So we indicate that in FN-induced MDA-MB-231, FAK regulate MMP-9 activity involving ERK and PI3K in its signaling cascade. Again FAK regulate cell migration by modulating MMP-9 activity.

Recently, several groups are trying to develop therapeutic strategies making FAK as a target molecule. These include inhibitory-RNA, small molecular inhibitory proteins or natural products. Different groups including our laboratory have demonstrated inhibitory role of some natural and/or synthetic compounds on Integrin mediated signaling $[29,30,46]$. But studies are required in detail to confirm their effects on FAK. We have tried to search whether these products can regulate FAK/MMP-9 signaling and thereby cell migration. In a part of this study we have focused on the effect of some natural products on FAK.

Interestingly, treatment of the natural products like ATRA, Curcumin and EGCG were found to decrease cell attachments. Results suggested ATRA, Curcumin and EGCG as inhibitor of FAK expression and MMP-9 activity in MDA-MB-231 breast cancer cell line.

We have also shown that FAK is the regulator of MMP9 activity. So here we may say that ATRA, Curcumin and EGCG downregulate MMP-9 activity probably by regulating FAK expression.

Cell migration is an important event which depends on efficient coordination between cell attachment and detachment on extracellular matrix [2]. FAK and MMP-9 are the key regulators of cell attachment-detachment and extracellular matrix invasion respectively [2]. Leu et al. have shown Curcumin can retard cell migration via downregulation FAK kinase activity [47]. In our system ATRA, Curcumin and EGCG was found to reduce cell migration, suggesting these natural products as regulators of migration of breast cancer cells.

\section{CONCLUSION}

In summary, we propose that Fibronectin induced MDA- 
MB-231 breast cancer cell migration is regulated by FAK. FAK is potent regulator of MMP-9 expression and activity. FN induces FAK through integrin $\alpha 5 \beta 1$. Again FAK transduces signal through ERK and PI3K by regulating their phosphorylation which regulate MMP-9 activity. Moreover, we have shown that Curcumin, ATRA and EGCG downregulate FAK expression MMP-9 activity and thereby cell migation. These signaling pathways may have crucial roles in modulating migration of breast cancer cells. The findings in this communication strengthen the role of FAK in regulation of cell migration and it's potential therapeutic implication in breast cancer.

\section{ACKNOWLEDGEMENTS}

The authors wish to express their thanks to Dr. Jaydip Biswas, Director, Chittaranjan National Cancer Institute, for continuous inspiration and financial support and to Defence Research \& Development Organisation (DRDO) (Grant no: DLS/81/48222/LSRB-145/ID/2008) for funding this project.

\section{REFERENCES}

[1] Schaller, M.D. (2001) Biochemical signals and biological responses elicited by the focal adhesion kinase. Biochimica Biophysica Acta, 1540, 1-21. doi:10.1016/S0167-4889(01)00123-9

[2] Mitra, S.K., Hanson, D.A. and Schlaepfer, D.D. (2005) Focal adhesion kinase: In command and control of cell motility. Nature Reviews Molecular Cell Biology, 6, 5668. doi:10.1038/nrm1549

[3] Ilic, D., Damsky, C.H. and Yamamoto, T. (1997) Focal adhesion kinase: At the crossroads of signal transduction. Journal of Cell Science, 110, 401-407.

[4] Luo, M. and Guan, J.L. (2010) Focal adhesion kinase: A prominent determinant in breast cancer initiation; progression and metastasis. Cancer Letters, 289, 127-139. doi:10.1016/j.canlet.2009.07.005

[5] Zhao, J. and Guan, J.L. (2009) Signal transduction by focal adhesion kinase in cancer. Cancer Metastasis Reviews, 28, 35-49. doi:10.1007/s10555-008-9165-4

[6] Clark, E.A. and Brugge, J.S. (1995) Integrins and signal transduction pathways: The road taken. Sciences, 268, 233239. doi:10.1126/science. 7716514

[7] Lee, Y.C., Cheng, T.H., Lee, J.S., Chen, J.H., Liao, Y.C., Fong, Y., Wu, C.H. and Shih, Y.W. (2011) Nobiletin; a citrus flavonoid; suppresses invasion and migration involving FAK/PI3K/Akt and small GTPase signals in human gastric adenocarcinoma AGS cells. Molecular and Cellular Biochemistry, 347, 103-115. doi:10.1007/s11010-010-0618-Z

[8] Chen, Y.J., Wei, Y.Y., Chen, H.T., Fong, Y.C., Hsu, C.J., Tsai, C.H., Hsu, H.C., Liu, S.H. and Tang, C.H. (2009) Osteopontin increases migration and MMP-9 up-regulation via alphavbeta3 integrin; FAK; ERK; and NF-kappaB-dependent pathway in human chondrosarcoma cells. Journal of Cell Physiology, 221, 98-108.

\section{doi: $10.1002 /$ jep. 21835}

[9] Meng, X.N., Jin, Y., Yu, Y., Bai, J., Liu, G.Y., Zhu, J., Zhao, Y.Z., Wang, Z., Chen, F., Lee, K.Y. and Fu, S.B. (2009) Characterisation of Fibronectin-mediated FAK signalling pathways in lung cancer cell migration and invasion. British Journal of Cancer, 101, 327-334. doi:10.1038/sj.bjc.6605154

[10] Ilic, D., Kovacic, B., Johkura, K., Schlaepfer, D.D., Tomasevic, N., Han, Q., Kim, J.B., Howerton, K., Baumbusch, C., Ogiwara, N., Streblow, D.N., Nelson, J.A., Dazin, P., Shino, Y., Sasaki, K. and Damsky, C.H. (2004) FAK promotes organization of fibronectin matrix and fibrillar adhesions. Journal of Cell Science, 117, 177-187. doi: $10.1242 /$ jes.00845

[11] Springman, E.B., Angleton, E.L., Birkedal-Hansen, H. and Van Wart, H.E. (1990) Multiple modes of activation of latent human fibroblast collagenase: Evidence for the role of a Cys 73 active-site zinc complex in latency and a "cysteine switch" mechanism for activation. Proceedings of the National Academy of Sciences USA, 87, 364-368. doi:10.1073/pnas.87.1.364

[12] Han, Y.P., Yan, C., Zhou, L., Qin, L. and Tsukamoto, H. (2007) A matrix metalloproteinase-9 activation cascade by hepatic stellate cells in trans-differentiation in the three-dimensional extracellular matrix. Journal of Biological Chemistry, 282, 12928-12939. doi:10.1074/jbc.M700554200

[13] Han, Y.P., Nien, Y.D. and Garner, W.L. (2002) Tumor necrosis factor-alpha-induced proteolytic activation of promatrix metalloproteinase- 9 by human skin is controlled by down-regulating tissue inhibitor of metalloproteinase1 and mediated by tissue-associated chymotrypsin-like proteinase. Journal of Biological Chemistry, 277, 27319 27327. doi:10.1074/jbc.M202842200

[14] Ramos-DeSimone, N., Hahn-Dantona, E., Sipley, J., Nagase, H., French, D.L. and Quigley, J.P. (1999) Activation of matrix metalloproteinase-9 (MMP-9) via a converging plasmin/stromelysin-1 cascade enhances tumor cell invasion. Journal of Biological Chemistry, 274, 13066-13076. doi:10.1074/jbc.274.19.13066

[15] Toth, M., Chvyrkova, I., Bernardo, M.M., HernandezBarrantes, S. and Fridman, R. (2003) Pro-MMP-9 activation by the MT1-MMP/MMP-2 axis and MMP-3: Role of TIMP-2 and plasma membranes. Biochemical and Biophysical Research Communications, 308, 386-395. doi:10.1016/S0006-291X(03)01405-0

[16] Segarra, M., Vilardell, C., Matsumoto, K., Esparza, J., Lozano, E., Serra-Pages, C., Urbano-Marquez, A., Yamada, K.M. and Cid, M.C. (2005) Dual function of focal adhesion kinase in regulating integrin-induced MMP-2 and MMP-9 release by human T lymphoid cells. FASEB Journal, 19, 1875-1877.

[17] Anderson, D.G., Li, X. and Balian, G.A. (2005) Fibronectin fragment alters the metabolism by rabbit intervertebral disc cells in vitro. Spine, 30, 1242-1246. doi:10.1097/01.brs.0000164097.47091.4c

[18] Chana, R.S., Martin, J., Rahman, E.U. and Wheeler, D.C. (2003) Monocyte adhesion to mesangial matrix modulates cytokine and metalloproteinase production. Kidney 
International, 63, 889-898. doi:10.1046/j.1523-1755.2003.00828.x

[19] Thant, A.A., Nawa, A., Kikkawa, F., Ichigotani, Y., Zhang, Y., Sein, T.T., Amin, A.R. and Hamaguchi, M. (2000) Fibronectin activates matrix metalloproteinase-9 secretion via the MEK1-MAPK and the PI3K-Akt pathways in ovarian cancer cells. Clinical \& Experimental Metastasis, 18, 423-428. doi:10.1023/A:1010921730952

[20] Han, S., Ritzenthaler, J.D., Sitaraman, S.V. and Roman, J. (2006) Fibronectin increases matrix metalloproteinase 9 expression through activation of c-Fos via extracellular-regulated kinase and phosphatidylinositol 3-kinase pathways in human lung carcinoma cells. Journal of Biological Chemistry, 281, 29614-29624. doi:10.1074/jbc.M604013200

[21] Shibata, K., Kikkawa, F., Nawa, A., Thant, A.A., Naruse, K., Mizutani, S. and Hamaguchi, M. (1998) Both focal adhesion kinase and c-Ras are required for the enhanced matrix metalloproteinase 9 secretion by fibronectin in ovarian cancer cells. Cancer Research, 58, 900-903.

[22] Sein, T.T., Thant, A.A., Hiraiwa, Y., Amin, A.R., Sohara, Y., Liu, Y., Matsuda, S., Yamamoto, T. and Hamaguchi, M. (2000) A role for FAK in the concanavalin a-dependent secretion of matrix metalloproteinase-2 and -9 . Oncogene, 19, 5539-5542.

[23] Xia, H., Nho, R.S., Judy, K., Jill, K. and Henke, C.A. (2004) FAK is upstream of PI-3-kinase/Akt in regulating fibroblast survival in response to contraction of type I collagen matrices via a $\beta 1$ integrin-viability signaling pathway. Journal of Biological Chemistry, 279, 3302433034. doi:10.1074/jbc.M313265200

[24] Shi, J., Zeng, X., Zhou, M. and Chen, Q. (2009) Activation of ERK-FAK signaling pathway and enhancement of cell migration involved in the early interaction between oral keratinocytes and candida albicans. Mycopathologia, 167, 1-7. doi:10.1007/s11046-008-9142-Z

[25] Das, S., Banerji, A., Frei, E. and Chatterjee, A. (2008) Rapid expression and activation of MMP-2 and MMP-9 upon exposure of human breast cancer cells (MCF-7) to fibronectin in serum free medium. Life Sciences, 82, 467476. doi:10.1016/j.1fs.2007.12.013

[26] Maity, G., Sen, T. and Chatterjee, A. (2011) Laminin induces matrix metalloproteinase-9 expression and activation in human cervical cancer cell line (SiHa). Journal of Cancer Research Clinical Oncology, 137, 347-357. doi:10.1007/s00432-010-0892-x

[27] Sen, T., Moulik, S., Dutta, A., Roy Choudhury, P., Banerji, A., Das, S., Roy, M. and Chatterjee, A. (2009) Multifunctional effect of epigallocatechin-3-gallate (EGCG) in downregulation of gelatinase-A (MMP-2) in human breast cancer cell line MCF-7. Life Sciences, 84, 194-204. doi:10.1016/j.1fs.2008.11.018

[28] Maity, G., Fahreen, S., Banerji, A., Roychoudhury, P., Sen, T., Dutta, A. and Chatterjee, A. (2010) Fibronectin-integrin mediated signaling in human cervical cancer cells (SiHa). Molecular and Cellular Biochemistry, 336, 6574. doi:10.1007/s11010-009-0256-5

[29] Sen, T., Dutta, A. and Chatterjee, A. (2010) EGCG downregulates Gelatinase-B (MMP-9) by involvement of FAK/
ERK, NF-kB and AP-I in the human breast cancer cell line MDA-MB-231. Anti Cancer Drugs, 21, 632-644. doi:10.1097/CAD.0b013e32833a4385

[30] Dutta, A., Sen, T. and Chatterjee A. (2010) All-trans retinoic acid (ATRA) downregulates MMP-9 by modulating its regulatory molecules. Cell Adhesion \& Migration, 4, 409-418.

[31] Lin, H.J., Su, C.C., Lu, H.F., Yang, J.S., Hsu, S.C., Ip, S.W., Wu, J.J., Li, Y.C., Ho, C.C., Wu, C.C. and Chung, J.G. (2010) Curcumin blocks migration and invasion of mouse-rat hybrid retina ganglion cells (N18) through the inhibition of MMP-2, -9, FAK, Rho A and Rock-1 gene expression. Oncology Reports, 23, 665-670.

[32] Miyazaki, T., Kato, H., Nakajima, M., Sohda, M., Fukai, Y., Masuda, N., Manda, R., Fukuchi, M., Tsukada, K. and Kuwano, H. (2003) FAK overexpression is correlated with tumour invasiveness and lymph node metasta sis in oesophageal squamous cell carcinoma. British Journal of Cancer, 89, 140-145. doi:10.1038/sj.bjc.6601050

[33] Lark, A.L., Livasy, C.A., Dressler, L., Moore, D.T., Millikan, R.C., Geradts, J., Iacocca, M., Cowan, D., Little, D., Craven, R.J. and Cance, W. (2005) High focal adhesion kinase expression in invasive breast carcinomas is associated with an aggressive phenotype. Modern Pathology, 18, 1289-1294. doi:10.1038/modpathol.3800424

[34] Cance, W.G., Harris, J.E., Iacocca, M.V., Roche, E., Yang, X., Chang, J., Simkins, S. and Xu, L. (2000) Immunohistochemical analyses of focal adhesion kinase expression in benign and malignant human breast and colon tissues: correlation with preinvasive and invasive phenotypes. Clinical Cancer Research, 6, 2417-2423.

[35] Beierle, E.A., Massoll, N.A., Hartwich, J., Kurenova, E.V., Golubovskaya, V.M., Cance, W.G., McGrady, P. and London, W.B. (2008) Focal adhesion kinase expression in human neuroblastoma: Immunohistochemical and realtime PCR analyses. Clinical Cancer Research, 14, 3299. 305. doi:10.1158/1078-0432.CCR-07-1511

[36] Ioachim, E., Charchanti, A., Briasoulis, E., Karavasilis, V., Tsanou, H., Arvanitis, D.L., Agnantis, N.J. and Pavlidis, N. (2002) Immunohistochemical expression of extracellular matrix components tenascin; fibronectin; collagen type IV and laminin in breast cancer: Their prognostic value and role in tumour invasion and progression. European Journal Cancer, 38, 2362-2370. doi:10.1016/S0959-8049(02)00210-1

[37] Reiske, H.R., Zhao, J., Han, D.C., Cooper, L.A. and Guan, J.L. (2000) Analysis of FAK-associated signaling pathways in the regulation of cell cycle progression. FEBS Letters, 486, 275-280. doi:10.1016/S0014-5793(00)02295-X

[38] Sieg, D.J., Hauck, C.R. and Schlaepfer, D.D. (1999) Required role of focal adhesion kinase (FAK) for integrinstimulated cell migration. Journal of Cell Sciences, 112, 2677-2691.

[39] Bang, O.S., Kim, E.J., Chung, J.G., Lee, S.R., Park, T.K. and Kang, S.S. (2000) Association of focal adhesion kinase with fibronectin and paxillin is required for precartilage condensation of chick mesenchymal cells. Biochemical and Biophysical Research Communications, 278, 


\section{2-529. doi:10.1006/bbrc.2000.3831}

[40] Maity, G., Roychoudhury, P., Sen, T., Ganguly, K.K., Sil, H. and Chatterjee, A. (2011) Culture of human breast cancer cell line (MDA-MB-231) on fibronectin-coated surface induces pro-matrix metalloproteinase-9 expression and activity. Tumour Biology, 32, 129-138. doi:10.1007/s13277-010-0106-9

[41] Chen, H.C., Appeddu, P.A., Isoda, H. and Guan, J.L. (1996) Phosphorylation of tyrosine 397 in focal adhesion kinase is required for binding phosphatidylinositol 3-kinase. Journal of Biological Chemistry, 271, 26329-26334. doi:10.1074/jbc.271.42.26329

[42] Schlaepfer, D.D. and Hunter, T. (1996) Evidence for in vivo phosphorylation of the Grb2 SH2-domain binding site on focal adhesion kinase by Src-family protein-tyrosine kinases. Molecular and Cellular Biology, 16, 56235633.

[43] Crowe, D.L. and Ohannessian, A. (2004) Recruitment of focal adhesion kinase and paxillin to betal integrin promotes cancer cell migration via mitogen activated protein kinase activation. BMC Cancer, $\mathbf{4}, 18$.

\section{ABBREVIATIONS}

ECM: Extracellular matrix,

ERK: Extracellular regulated kinase,

FAK: Focal adhesion kinase,

FBS: Fetal bovine serum,

FITC: Fluorecin isothiocyanate,

FN: Fibronectin,

GAPDH: Glyceraldehyde phosphate dehydrogenase,

\section{doi:10.1186/1471-2407-4-18}

[44] Serrels, B., Serrels, A., Brunton, V.G., Holt, M., McLean, G.W., Gray, C.H., Jones, G.E. and Frame, M.C. (2007) Focal adhesion kinase controls actin assembly via a FERMmediated interaction with the Arp2/3 complex. Nature Cell Biology, 9, 1046-1056. doi:10.1038/ncb1626

[45] Reiske, H.R., Kao, S.C., Cary, L.A., Guan, J.L., Lai, J.F. and Chen, H.C. (1999) Requirement of phosphatidylinositol 3-kinase in focal adhesion kinase-promoted cell migration. Journal of Biological Chemistry, 274, 1236112366. doi:10.1074/jbc.274.18.12361

[46] Siu, L.L, Burris, H.A., Mileshkin, L.R., et al. (2008) A phase I clinical, pharmacokinetic (PK) and pharmacodynamic (PD) evaluation of PF-00562271 targeting focal adhesion kinase (FAK) in patients (pts) with advanced solid tumors. Journal of Clinical Oncology, 26, 3534.

[47] Leu, T.H., Su, S.L, Chuang, Y.C. and Maa, M.C. (2003) Direct inhibitory effect of curcumin on Src and focal adhesion kinase activity. Biochemical Pharmacology, 66, 2323-2331. doi:10.1016/j.bcp.2003.08.017

HRP: Horseradish peroxidase,

MMP: Matrix metalloproteinase,

PI-3K: Phosphatidyl inositol 3 kinase,

SFCM: Serum free culture media,

SiRNA: Small interfering RNA,

TIMP: Tissue inhibitor of Metalloproteinases,

Tyr: Tyrosine. 